\title{
COMPARISON OF MANIFESTATIONS OF GIARDIA AND ASCARIS INFESTATIONS BETWEEN BOTH GENDERS PRESENTING WITH DIARRHEA
}

\author{
Kanwal Jehanzeb, Zia Ul Haq*, Saeed Zaman Khattak**, Sajid Ali Shah***, Munir Akmal Lodhi ${ }^{* * * *}$, Nadeem Ashraf*** \\ Combined Military Hospital Gilgit/National University of Medical Sciences (NUMS) Pakistan, *Combined Military Hospital \\ Gujranwala/National University of Medical Sciences (NUMS) Pakistan, ${ }^{* *}$ Combined Military Hospital Kharian/National University of \\ Medical Sciences (NUMS) Pakistan, ${ }^{* * *}$ Combined Military Hospital Skardu/National University of Medical Sciences (NUMS) Pakistan, \\ ****Fouji Foundation Hospital, Rawalpindi Pakistan
}

\begin{abstract}
Objective: To assess the occurrence and intensity of Giardia and Ascaris infestations in children of both genders reporting with diarrhea.

Study Design: Comparative cross sectional study.

Place and Duration of Study: Paediatrics department, Combined Military Hospital, Gilgit, from Jul 2016 to Jul 2018.

Methodology: Patients of either gender with worm infestation were included in the study. Patients more than 13 years old were excluded. The sampling technique used was non probability consecutive sampling. The stool examination (R/E) for the diagnosis of worm infestation was done. Stratification was done with regards to age, mother education, gender, type of water used and post stratification chi square test was applied. $p$-value was 0.613 when calculated for the manifestation between both genders. $p$-value $\leq 0.05$ was considered significant.

Results: Total number of patients in our study was 100. Among them, males were $65(65 \%)$ and females were 35 $(35 \%)$. Mean age of patients in our study was $4.20 \pm 2.61$ years (Mean $\pm \mathrm{SD}$ ). Abdominal pain being most common symptom in $43(43 \%)$ of patients. Majority of the patients were from 2 to 10 years of age, 79 (79\%). Helminthic infestation was the most common observed in 52 (52\%) whereas Protozoal infestation was observed in 48 (48\%) patients. The most common parasite isolated was Giardia 41 (41\%) followed by Ascaris 36 (36\%). p-value of 0.613 was found between both gender.

Conclusion: In our study Helminthic infestation was more common. The most common parasite isolated was Giardia followed by Ascaris.
\end{abstract}

Keywords: Ascaris, Children, Giardia, Protozoa, Worm infestation.

This is an Open Access article distributed under the terms of the Creative Commons Attribution License (http://creativecommons.org/licenses/by/4.0), which permits unrestricted use, distribution, and reproduction in any medium, provided the original work is properly cited.

\section{INTRODUCTION}

Intestinal parasitic infection of children is a global health problem, particularly in developing world. The intestinal parasitic infection can be broadly divided into protozoal infection and helminthic infestation. The most important protozoa are Giardia Lamblia and Entamoeba Histolytica. The route of transmission of most of intestinal parasites is oro-fecal. The important risk factors include low socioeconomic status, poor sanitation, lack of hand washing and overcrowding1. Parasitic intestinal infections are important cause of mortality and morbidity in children, especially in school going children. It is estimated that

Correspondence: Dr Kanwal Jehanzeb, Department of Paediatrics, Combined Military Hospital, Mangla Pakistan

Received: 07 May 2019; revised received: 18 Sep 2019; accepted: 10 Oct 2019 about $25 \%$ of the world population is at risk of parasitic infection. Despite such a huge burden of intestinal parasitic infection little attention has been paid all over the world for the prevention and eradication of this problem ${ }^{2}$. Protozoal infections are responsible for acute and chronic diarrhea which may further lead to malnutrition; increasing mortality manifold. In the developed world about $3 \%$ of the population is infected with Giardia whereas this figure approaches to $30 \%$ in the developing countries ${ }^{3}$. About ten thousands deaths are estimated to occur annually due to intestinal Entamoeba infection ${ }^{4}$. Similarly millions of children, mostly school going, are suffering from helminthic infestation ${ }^{1}$.

The term parasitic disease is used if the patient is infected with some parasite and is 
suffering from signs and symptoms related to that parasite. If patient is infected with intestinal parasite but is asymptomatic then the term parasitic infection is used. Clinical manifestations of the parasitic disease may not be the same in all patients as it depend on multiple factors including parasite pathogenicity, parasite load, nutritional status of host, immune system of the infected person and the resistance of the parasite to local defense system 5 . The target for parasitic infections is mostly children. Loss of school days, low grades, impaired cognition, short stature and anemia are observed more frequently in parasite infected children. The exact mechanism is not known but iron deficiency resulting from parasitic infection may be responsible for all these complications. Also these complications are more sever in those children who are untreated and remain infected for a prolonged period. This is the reason that periodic deworming is recommended in all school aged children where parasitic infections are endemic ${ }^{6}$.

Recently, attention has been paid to the long term effects of intestinal parasitic infection. Chronic intestinal parasitic infections affect local neurotransmitter synthesis and uptake, interfere with local immunity and also inhibit mast cell activation. Also it has been claimed that chronic intestinal parasitic infestations increase the chances of common chronic gastrointestinal disturbances like gastro esophageal reflux disease, inflammatory bowel disease and also these infections have been implemented in the pathogenesis of some non-gastro intestinal diseases like chronic fatigue syndrome ${ }^{7}$. Intestinal parasitic infections not only present with medical complications but also some may present with surgical complications in the form of appendicitis, intestinal obstruction, biliary tract obstruction, pancreatic duct obstruction and intussusception. For the diagnosis of intestinal parasitic infection history is the cornerstone. In history risk factors are dig out which further lead to appropriate investigations. Microscopy, ELIZA and PCR are the different methods to confirm the diagnosis ${ }^{8}$. Different medications are used for the treatment and prevention of parasitic infections. For most common worm infestation Mebendazole and Albendazole are the drug of choice. Metronidazole is the drug of choice for common intestinal protozoal infection. Re infection is common if clean water supply is not available and the hygienic conditions are not good 9 .

The rationale behind our study was to highlight the burden of parasitic intestinal infection in our set up. These infections are easy to diagnose and treat. If they are not timely diagnosed and treated, may lead to long term morbidity and mortality.

\section{METHODOLOGY}

This cross sectional study was carried out in the department of Paediatrics, Combined Military Hospital, Gilgit. The study period extended from July 2016 to July 2018. Sample size was calculated using World Health Organization sample size calculator with $95 \%$ confidence interval, anticipated population proportion was estimated to be $41 \%$ calculated to be 100 and absolute precision required was $10 \%$. Sampling technique used was non probability consecutive sampling. Patients of either gender having age group ranging from 6 months to 13 years of age and with stool routine examination positive for parasites were included in the study. Children having any type of infection or active disease were excluded from our study. Source of water was classified as Nulla (drinking water collected from river or springs etc), tap water (government supply) and boiled water. The prominent sign and symptoms were included as abdominal pain, pica (eating clay or any non-nutritive objects) and diarrhea if the presenting symptoms were that of loose motion. Age of the study participant was divided into three groups as less than 2 years, between 2 to 10 years and more than 10 years. The parasites were divided into protozoa which are unicellular and included Giardia and E. Histolytica and helminthes which included Ascaris, Enterobius, H. Nana, Trichiuris and T. Saginata. Fresh stool samples were collected and sent to laboratory for examination. Examination under microscope was carried out by pathologist. 
Data was collected on a specially designed proforma. Approval from the hospital's ethical and research committee was taken; informed consent was obtained from the parents/guardians of all patients participating in study, after explai-

\begin{tabular}{|c|c|}
\hline Age in years & n (\%) \\
\hline Mean \pm SD & $4.20 \pm 2.61$ \\
\hline \multicolumn{2}{|l|}{ Gender } \\
\hline Male & $65(65 \%)$ \\
\hline Female & $35(35 \%)$ \\
\hline \multicolumn{2}{|l|}{ Water Supply } \\
\hline Nulla/Spring & $39(39 \%)$ \\
\hline Tap Water & $55(55 \%)$ \\
\hline Boiled Water & $6(6 \%)$ \\
\hline \multicolumn{2}{|l|}{ Signs and Symptoms } \\
\hline Abdominal pain & $43(43 \%)$ \\
\hline Diarrhea & $18(18 \%)$ \\
\hline Pica & $37(37 \%)$ \\
\hline Intestinal obstruction & $2(2 \%)$ \\
\hline \multicolumn{2}{|c|}{ Parasitic Infestation Protozoa $(\mathrm{n}=48)$} \\
\hline Giardia Lamblia & $41(41 \%)$ \\
\hline Entamoeba Histolytica & $7(7 \%)$ \\
\hline Helminthic Infestation $(n=52)$ & \\
\hline Ascaris Lumbricoides & $36(36 \%)$ \\
\hline Hyemenolepis Nana & $10(10 \%)$ \\
\hline Trichiuris Trichiura & $3(3 \%)$ \\
\hline Taenia Saginata & $2(2 \%)$ \\
\hline Enterobius Vermicularis & $1(1 \%)$ \\
\hline \multicolumn{2}{|l|}{ Maternal Education } \\
\hline Under Matric & $39(39 \%)$ \\
\hline Matric & $28(28 \%)$ \\
\hline Intermediate & $10(10 \%)$ \\
\hline Graduation & $20(20 \%)$ \\
\hline Post Graduation & $3(3 \%)$ \\
\hline \multicolumn{2}{|l|}{ Age Group } \\
\hline$<2$ years & $17(17 \%)$ \\
\hline 2-10 years & $79(79 \%)$ \\
\hline$>10$ years & $4(4 \%)$ \\
\hline
\end{tabular}

ning the purpose and benefits of study. Patients fulfilling the inclusion criteria were included in the study.

All participants were subjected to detailed history including sign and symptoms, source of water, type of parasites, maternal education and examination. Exclusion criteria were strictly adhered for controlling confounders and avoiding any inclination in the study. Due respect was given to the patients and all cultural, conventional and civil values were kept in mind. Confidentiality was given due importance.

Data collected was entered in SPSS (23.0). Continuous variable like age was measured by mean and standard deviation. Qualitative variables like gender, maternal education, source of water, type of parasites, sign and symptoms were measured as frequency and percentages. Effect modifiers like patient age, gender, maternal education and source of water were stratified. Post stratification chi-square test was applied. $p$-value $\leq 0.05$ was considered significant.

\section{RESULTS}

Total number of participants in our study was 100. Among those, males were $65(65 \%)$ and females were $35(35 \%)$. Mean age of patients in study population was $4.20 \pm 2.61$ years (Mean \pm $\mathrm{SD})$. Abdominal pain was the most common symptom observed in $43(43 \%)$ of patients. Majority of the patients were from 2 to 10 years 79 (79\%) of age. Helminthic infestations was the most common observed in $52(52 \%)$ whereas protozoal infestation was observed in $48(48 \%)$ patients. The most common parasite isolated was Giardia Lamblia 41 (41\%) followed by Ascaris Lumbricoides $36(36 \%)$ as mentioned in table-II.

\section{DISCUSSION}

The study was carried out in part of northern areas of Pakistan. During 2 years tenure 100 stool samples were positive for intestinal parasites. Most of the patients were male. The age of study participants was [Mean \pm SD] $4.20 \pm 2.61$ years. The most common organism observed in our study was Giardia lamblia ( $41 \%$ ) followed by Ascaris lumbricoides (36\%). A study conducted in Peshawar had the same results, where Giardia Lamblia (19.4\%) was the most common parasitic infestation followed by Entamoeba Histolytica $(12.5 \%)^{10}$. Unlike our study, H. Nana was considered the most common parasite $(6 \%)$ in a study conducted in Rawalpindi. The [Mean \pm SD] age of their study population was $5 \pm 2.8$ years ${ }^{11}$. In a different study carried out by Shah et al, in Hangu District, Giardia lamblia (57\%), like our 
study, was found to be the most common intestinal parasite. The other intestinal parasites detected in their study were Entamoeba histolytica in about $19 \%$ patients, H.nana in $9 \%$ patients, Taenia saginata in $7 \%$ patients, Ascaris and Trichuris trichura in $2 \%$ of patients. In their study they included both children and adults and the stool examination was carried out in patients presen- observed was loose motion $(10 \%)^{14}$. Another study by Steven et al, unlike our study, revealed protozoal infections to be the most common intestinal parasitic infection. However similar to our study, the most common symptoms observed in their study were G.I.T (gastrointestinal tract) related like abdominal pain and diarrhea (observed in up to $83 \%$ of patients) $)^{15}$. Sometimes

Table-II: Post stratification test for different variables applying fisher exact test $\mathbf{n}(\%)$.

\begin{tabular}{|c|c|c|c|c|c|c|c|c|}
\hline Gender & Giardia & E.Histolytica & Ascaris & T.Trichura & H.Nana & T.Saginata & Enterobius & $p$-value \\
\hline Male & 25 & 6 & 24 & 3 & 6 & 1 & - & $0=2$ \\
\hline Female & 16 & 1 & 12 & - & 4 & 1 & 1 & 0.33 \\
\hline \multicolumn{9}{|l|}{ Age Group } \\
\hline$<2$ years & 4 & 3 & 8 & 1 & - & 1 & - & \multirow{3}{*}{0.04} \\
\hline 2-10 years & 36 & 3 & 28 & 2 & 9 & - & 1 & \\
\hline$>10$ years & 1 & 1 & - & - & 1 & 1 & - & \\
\hline \multicolumn{9}{|c|}{ Maternal Education } \\
\hline$<$ Matric & 16 & 4 & 13 & 3 & 2 & - & 1 & \multirow{5}{*}{0.80} \\
\hline Matric & 10 & 1 & 11 & - & 4 & 2 & - & \\
\hline Intermed & 5 & - & 4 & - & 1 & - & - & \\
\hline Graduate & 9 & 2 & 7 & - & 2 & - & - & \\
\hline Post Grad & 1 & - & 1 & - & 1 & - & - & \\
\hline \multicolumn{9}{|c|}{ Source of Water } \\
\hline Nullah & 12 & 5 & 12 & 2 & 7 & - & 1 & \multirow{3}{*}{0.03} \\
\hline Tap Water & 26 & 1 & 23 & 1 & 2 & 2 & - & \\
\hline Boil Water & 3 & 1 & 1 & - & 1 & - & - & \\
\hline \multicolumn{9}{|c|}{ Signs and Symptoms } \\
\hline Abd Pain & 16 & 2 & 17 & 1 & 6 & 1 & - & \multirow{4}{*}{0.80} \\
\hline Diarrhea & 8 & 1 & 5 & 1 & 1 & - & 1 & \\
\hline Pica & 17 & 4 & 11 & 1 & 3 & 1 & - & \\
\hline Int Obstr & - & - & 2 & - & - & - & - & \\
\hline
\end{tabular}

ting with loose motion ${ }^{12}$. Similarly in a study from Lahore 93 patients had positive stool examination for intestinal parasites. In contrast to our study protozoal infections were more common in their children as compared to helminthiasis i.e. 74 vs 18, respectively. However like our study the most common parasites isolated were Giardia lamblia (69\% of all protozoal infections) followed by Ascaris (50\% of all helminthic infestations) ${ }^{13}$.

The signs and symptoms observed in our study were abdominal pain (43\%), pica (37\%) and diarrhea (17\%). 2 of the patients with Ascariasis presented with intestinal obstruction. They were referred to surgical specialist and were operated with uneventful recovery. In an Indian study, unlike our study, the most common complaint patients with helminthic infestation may present with acute abdomen with sign and symptoms of intestinal obstruction. The diagnosis may be suspected based on history in an endemic area. It

Table-III: Giardia and ascaris infestation in both genders.

\begin{tabular}{l|c|c|c}
\hline & Male & Female & $p$-value \\
\hline Giardia & $25(61 \%)$ & $16(39 \%)$ & \multirow{2}{*}{0.613} \\
\hline Ascaris & $24(67 \%)$ & $12(33 \%)$ & \\
\hline
\end{tabular}

may then be confirmed with ultrasonography of abdomen. The treatment in these cases may be both conservative and sometime laparotomy may be required. In the first case the outcome is better but in the last case the mortality and morbidity is high $^{16}$. In our study too, two patients presented with acute abdomen and were operated for intes- 
tinal obstruction. Per operative findings included bolus of ascariasis.

The risk factors in our study included low maternal education, unprocessed or un boiled water and male gender but none were statistically significant. Higher incidence of parasitic infection was observed in age group 2 to 10 years, which was statistically significant with $p$-value $<0.05$. Most of the mothers in our study were either under Matric or had cleared Matriculation. In the literature too, lower education level of mothers have been associated with children presenting with parasitic infections. In a Turkish study education level of most of the mothers of children with parasitic infections was primary or secondary school ${ }^{17}$. However in their study no statistically significant relation was found between age group and parasitic infection whereas in our study it was statistically significant. Like our study, an Indian study also revealed that majority of the children with intestinal parasitic infestations, were using spring or tap water. Few children using boiled water were found to have parasitic infections ${ }^{18}$. Another study conducted in rural Peshawar revealed prevalence of Ascaris lumbricoides $(45.5 \%)$ in a majority of primary school children ${ }^{19}$.

\section{CONCLUSION}

Most of the patients with parasitic infestations were between 2 to 10 years of age. The most common protozoal infection was with Giardia and the most common helminthic infestation was with Ascaris. Most of the patients using spring or tape water were found to have parasitic infections.

\section{CONFLICT OF INTEREST}

This study has no conflict of interest to be declared by any author.

\section{REFERENCES}

1. Erismann S, Diagbouga S, Odermatt P, Knoblauch AM. Prevalence of intestinal parasitic infections and associated risk factors among schoolchildren in the Plateau Central and CentreOuest regions of Burkina Faso. Parasites \& vectors 2016; 9(1): $554-60$.

2. Jourdan PM, Lamberton PH, Fenwick A, Addiss DG. Soil- transmitted helminth infections. Lancet 2018; 391(10117): 252-65.

3. Fletcher SM, Stark D, Harkness J, Ellis J. Enteric protozoa in the developed world: a public health perspective. Clinical Microbiol Review 2012; 25(3): 420-49.

4. Vos T, Barber RM, Bell B, Bertozzi-Villa A, Biryukov S, Bolliger I, et al. Global, regional, and national incidence, prevalence, and years lived with disability for 301 acute and chronic diseases and injuries in 188 countries, 1990-2013: a systematic analysis for the Global Burden of Disease Study 2013. Lancet 2015; 386(9995): 743-50.

5. Wang Y. Pathophysiology of Parasitic Disease. In Radiology of Parasitic Diseases 2017 (pp. 9-11). Springer, Dordrecht. https:// www. springer.com/gp/book/9789402409093.

6. Pabalan N, Singian E, Tabangay L, Jarjanazi H, Boivin MJ, Ezeamama AE. Soil-transmitted helminth infection, loss of education and cognitive impairment in school-aged children: A systematic review and meta-analysis. PLoS Neglected Tropical Diseases 2018; 12(1): e0005523.

7. Blitz J, Riddle MS, Porter CK. The risk of chronic gastrointestinal disorders following acute infection with intestinal parasites. Front Microbiol 2018; 9(17): 1-8.

8. Garcia LS, Arrowood M, Kokoskin E, Paltridge GP, Pillai DR, Procop GW, et al. Laboratory diagnosis of parasites from the gastrointestinal tract. Clinical Microbiol Review 2018; 31(1): e00025-17.

9. Hürlimann E. Effect of an integrated intervention package of preventive chemotherapy, community-led total sanitation and health education on the prevalence of helminth and intestinal protozoa infections in Côte d'Ivoire. Parasit Vectors 2018; 11(1): 115-18.

10. Haider J, Mohammad NS, Nazli R, Fatima S, Akhtar T. Prevalence of parasitic infestation in children of a rural community of peshawar. kmuj: Khyber Med University J 2018; 10(1): 14-8.

11. Javaid MK. Prevalence of Intestinal Parasitic Infestations Among Children. J Raw Med Coll 2016; 20(3): 216-18.

12. Shah SA, Marwat SA, Rashid HU, Hussain A, Khurshid K. Importance of microscopic stool examination in patients with diarrhoea. J Ayub Med Coll Abbott 2014; 26(4): 478-80.

13. Hafeez S, Ali Z, Zafar A. Prevalence of Intestinal Parasitic Infestation at Children Hospital of Lahore. Pak J Med Health scien 2018; 12(2): 645-48.

14. Praharaj I, Sarkar R, Ajjampur SS, Roy S, Kang G. Temporal trends of intestinal parasites in patients attending a tertiary care hospital in south India: A seven-year retrospective analysis. Ind J Med Res 2017; 146(1): 111-20.

15. Miller SA, Rosario CL, Rojas E, Scorza JV. Intestinal parasitic infection and associated symptoms in children attending day care centres in Trujillo, Venezuela. Trop Med Int Health 2003; 8(4): 342-47.

16. Villamizar E, Mendez M, Bonilla E, Varon H, de Ontra S. Ascaris lumbricoides infestation as a cause of intestinal obstruction in children: experience with 87 cases. J Pediatr Surg 1996; 31(1): 201-5.

17. Okyay P, Ertug S, Gultekin B, Onen O, Beser E. Intestinal parasites prevalence and related factors in school children, a western city sample-Turkey. BMC Pub Health 2004; 4(1): 64-69.

18. Chanu NO, Singh TS, Dutta S. Occurrence of intestinal parasitic infections with gastrointestinal symptoms in children in sikkim. Int J Sci Res 2018; 6(12): 43-48.

19. Ikram U, Ghulam S, Sabina A. Intestinal Worm Infestation in primary school children in rural Peshawar. Gomal J Med Sci 2009; 7(2): 132-36. 